\title{
Wpływ kształtu narzędzia w metodzie zgrzewania FSW stopu Al na jakość zgrzein
}

\author{
The influence of a tool shape in the FSW method of Al alloy \\ on weld quality
}

\section{Streszczenie}

W pracy przedstawiono wyniki badań zgrzewania metodą FSW (ang. Friction Stir Welding) stopu aluminium typu 6082. Analizowano wpływ kształtu narzędzia na jakość zgrzein. Zaprojektowano i wykonano modułowe narzędzia o różnej geometrii zarówno powierzchni tarcia oprawki, jak i narzędzia roboczego. Testy zgrzewania wykonano dla złączy nakładkowych i doczołowych na podkładce przy zmiennych parametrach procesu. Wykazano, iż zarówno geometria powierzchni tarcia, jak i kształt narzędzia roboczego istotnie wpływają na wygląd lica oraz jakość połączenia zgrzewanego.

Słowa kluczowe: zgrzewanie tarciowe z przemieszaniem (FSW); stop Al; zgrzeina tarciowa

\begin{abstract}
The paper presents the results of Friction Stir Welding Al 6082 alloy. The research focused on the influence of the tool shape on the quality of welds. Modular tools with different geometry for the shoulder surface and the probe were designed and made. Welding tests were performed for overlap and strapped butt joints and variable process parameters. Studies concluded that both the geometry of the shoulder and the probe significantly affect the appearance of the face and the quality of the welded connection.
\end{abstract}

Keywords: Friction Stir Welding; Al alloy; friction weld

\section{Wstęp}

Zgrzewanie tarciowe z przemieszaniem FSW (ang. Friction Stir Welding), zostało opracowane w 1991 roku w Wielkiej Brytanii. Od tego momentu metoda ta jest nieustannie badana oraz rozwijana. Początkowo służyła do łączenia stopów aluminium. Dzisiaj umożliwia m.in. zgrzewanie stali, tytanu, miedzi oraz wykonywanie połączeń różnoimiennych, jak aluminium-miedź czy aluminium-stal.

Głównymi zaletami FSW jest możliwość łączenia metali trudnospawalnych oraz uzyskiwanie wysokiej i powtarzalnej jakości połączeń. Proces spajania odbywa się $w$ temperaturze niższej od temperatury topienia materiału rodzimego. Pozwala to uniknąć takich wad jak pęknięcia gorące, porowatość gazowa czy odkształcenia spowodowane krzepnięciem metalu. Umożliwia to też wykonywanie połączeń w każdej pozycji, ze względu na brak jeziorka ciekłego metalu. W porównaniu do spawania wyższa wytrzymałość strefy wpływu ciepła tego typu połączeń korzystnie wpływa na nośność konstrukcji. Co więcej, jest to technologia czysta ekologicznie, gdyż w jej trakcie nie powstają dymy czy gazy. W porównaniu do spawania metoda ta nie wymaga odpowiedniego przygotowania powierzchni, stosowania gazów osłonowych czy materiałów dodatkowych. Powyższe zalety w połączeniu z większym bezpieczeństwem, energooszczędnością procesu sprawiają, że technologia FSW jest coraz szerzej stosowana. Obecnie za jej pomocą wykonuje się obręcze kół, karoserie pojazdów samochodowych, układy zawieszenia, cysterny oraz statki [1]. Bardzo duże perspektywy zastosowania tej technologii związane są z przemysłem lotniczym i kosmicznym, gdzie metodą FSW zgrzewane są skrzydła, kadłuby oraz zbiorniki na paliwo.

Dominującą grupę materiałów zgrzewanych metodą FSW

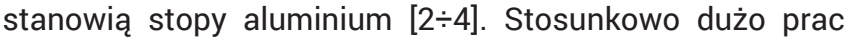
badawczych poświęconych jest modelowaniu zjawisk występujących $\mathrm{w}$ trakcie tego procesu, tj. rozkład temperatury i naprężeń, przepływ materiału $[5,6]$ oraz strukturze i właściwościom zgrzein [7]. Natomiast w niniejszej pracy skoncentrowano się na badaniach wpływu kształtu narzędzia roboczego i parametrów procesu na formowanie się poprawnych zgrzein i o wysokiej estetyce. Wówczas, tego typu połączenia nie tylko spełniają wysokie wymagania eksploatacyjne, ale również minimalizują obróbkę wykańczającą.

Mgr inż. Krzysztof Mazurkiewicz - Smart Trading Company Sp. z o.o., dr inż. Mariusz Bober - Politechnika Warszawska.

Autor korespondencyjny/Corresponding author: krzysztofm@smarttrading.pl 


\section{Stosowane materiały i urządzenia}

\section{Opracowanie i wykonanie narzędzi roboczych}

Opracowując narzędzie robocze przyjęto następujące założenia. Pierwszym z nich był podział narzędzia na oprawkę z odpowiednim kołnierzem formującym zgrzeinę i wymienny trzpień. Modułowość narzędzia umożliwia przetestowanie większej ilości wariantów trzpień-kołnierz. Projekt oprawki zakładał także możliwość zamocowania jej we wrzecionie frezarki oraz zaplanowano wykonanie w niej przelotowego otworu pozwalającego na wybicie trzpienia.

$\mathrm{Na}$ podstawie powyższych kryteriów, przeglądu literatury $[8,9]$ oraz własnego doświadczenia zaprojektowano dwa typy oprawek o rożnej geometrii powierzchni trącej, tj. wklęsłą i helisoidalną. Średnica kołnierza oprawki wynosiła $20 \mathrm{~mm}$ (rys. 1). Zaprojektowany sposób mocowania zarówno trzpienia, jak i oprawki to znany z narzędzi do obróbki skrawaniem uchwyt Weldon. Oprawka wklęsła (rys. 1a), jest jedną z najczęściej spotykanych wśród narzędzi do zgrzewania tarciowego. Taki kształt kołnierza bardzo dobrze zapobiega wypływaniu materiału na zewnątrz zgrzeiny. Oprawka wypukła (rys. 1b) posiada helisę wysuniętą na wysokość $0,5 \mathrm{~mm}$ położoną na płaskim kołnierzu. Ma ona za zadanie przemieszczać wypływający materiał do środka zgrzeiny.

Następnie zaprojektowano sześć wymiennych trzpieni (rys. 2). Część robocza każdego z nich wynosiła 6 lub $7 \mathrm{~mm}$. Pierwsze cztery zaprojektowane trzpienie posiadały helisę odłożoną na ściętym stożku. Kształt ten miał wymuszać ruch materiału w głąb zgrzeiny.

a)

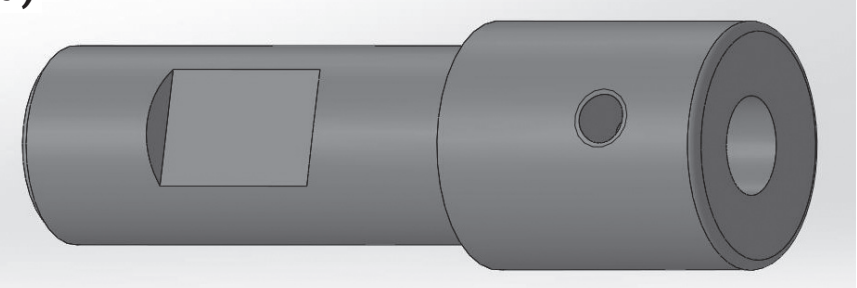

Projekty oprawek i trzpieni roboczych wykonano w programie SolidWorks. Obróbkę narzędzi przygotowano przy pomocy programu Esprit. Kod NC został wygenerowany przez postprocesor na podstawie zaprojektowanej ścieżki narzędzia. Obróbkę oprawek i trzpieni wykonano na tokarce Haas ST10 oraz centrum obróbczym Haas VF3. Jako materiał zastosowano stal HS6-5-2 (SW7M). Po obróbce skrawaniem narzędzia poddano zabiegowi utwardzania cieplnego.

\section{Zgrzewane materiały}

Stop aluminium o oznaczeniu 6082 i składzie chemicznym przedstawionym w tabeli 1 stanowił materiał zgrzewany. Do badań przygotowano dwa typy złączy: nakładkowe (nak) oraz doczołowe na podkładce (dnp) (rys. 3). Grubość nakładki wynosiła $4 \mathrm{~mm}$ a podstawy $6 \mathrm{~mm}$.

a)

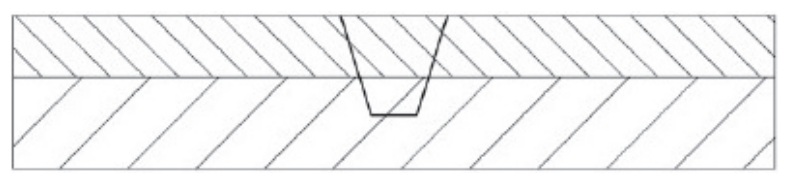

b)

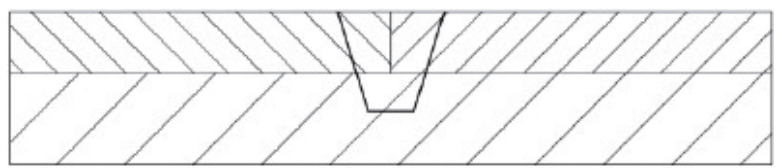

Rys. 3. Rodzaje złączy zgrzewanych: a) nakładkowe (nak), b) doczołowe z podkładką (dnp)

Fig. 3. Types of welded joints: a) overlap (nak), b) strapped butt (dnp)

b)

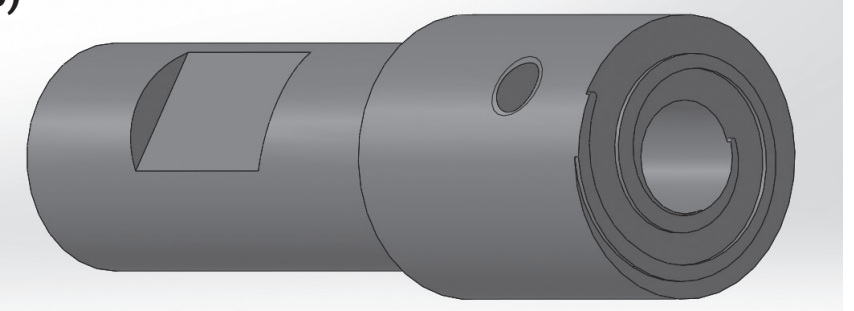

Rys. 1. Oprawki trzpieni o różnej geometrii powierzchni trącej: a) wklęsła, b) helisoidalna Fig. 1. Probe holders with different geometry of the shoulder surface: a) concave, b) helix

a)

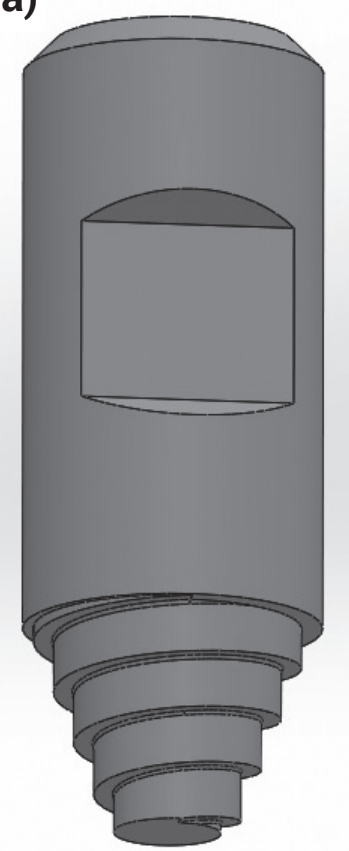

b)

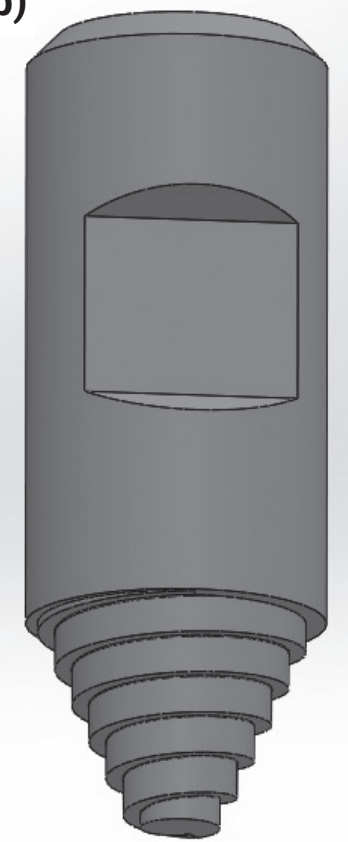

c)

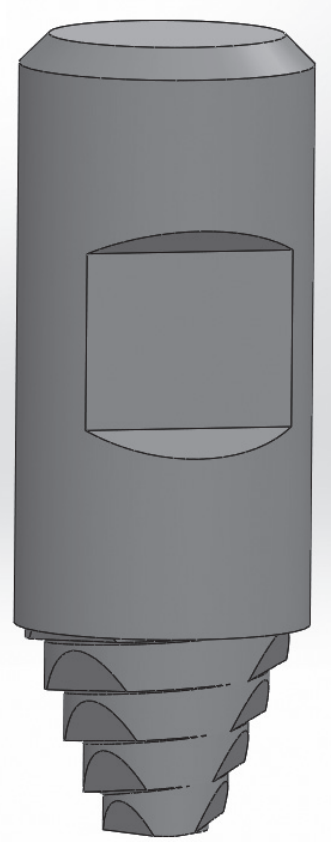

d)

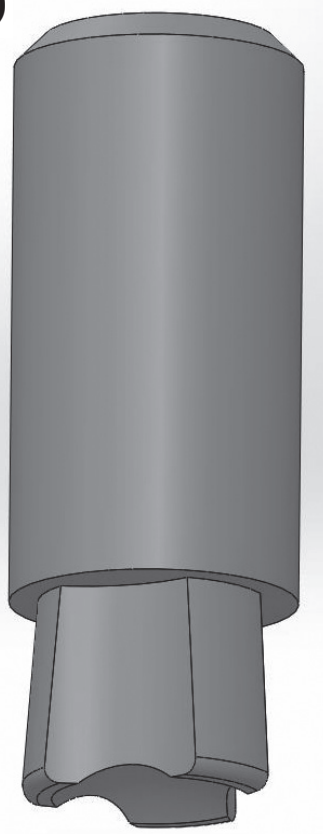

Rys. 2. Trzpienie robocze: a) helisoidalny $7 \mathrm{~mm}$, b) helisoidalny $6 \mathrm{~mm}, \mathrm{c}$ ) helisoidalny ścięty, d) trójramienny Fig. 2. Probe: a) helix $7 \mathrm{~mm}$, b) helix $6 \mathrm{~mm}, \mathrm{c}$ ) helix sheared, d) three-armed 
Tablica I. Skład chemiczny stopu 6082 wg PN-EN 573-3 [7]

Table I. Chemical composition of 6082 alloy according to PN-EN 573-3 [7]

\begin{tabular}{|c|c|c|c|c|c|c|c|c|}
\hline Si & Fe & Cu & Mn & Mg & Cr & Zn & Ti & Al \\
\hline $0,7 \div 1,3$ & $0,45 \div 0,55$ & $0,08 \div 0,12$ & $0,4 \div 1$ & $0,6 \div 1,2$ & $0,23 \div 0,27$ & $0,18 \div 0,22$ & $0,08 \div 0,12$ & reszta \\
\hline
\end{tabular}

Tablica II. Parametry procesu zgrzewania - wybór oprawki

Table II. Parameters of the welding process - selection of the probe holders

\begin{tabular}{|c|c|c|c|c|c|c|}
\hline Nr próby & Oprawka & Trzpień & Typ połączenia & $\begin{array}{c}\text { Posuw pionowy } \\
\text { Fz [mm/min] }\end{array}$ & $\begin{array}{c}\text { Posuw poziomy } \\
\text { Fx [mm/min] }\end{array}$ & $\begin{array}{c}\text { Prędkość obrotowa } \\
\text { [obr./min] }\end{array}$ \\
\hline 1 & wklęsła & helisoidalny & dnp & 8 & 125 & 800 \\
\hline 2 & helisoidalna & helisoidalny & dnp & 8 & 125 & 800 \\
\hline 3 & wklęsła & helisoidalny & dnp & 8 & 160 & 630 \\
\hline 4 & helisoidalna & helisoidalny & dnp & 8 & 160 & 630 \\
\hline 5 & wklęsła & helisoidalny ścięty & dnp & 8 & 160 & 630 \\
\hline 6 & wklęsła & helisoidalny ścięty & dnp & 8 & 80 & 630 \\
\hline
\end{tabular}

Tablica III. Parametry procesu zgrzewania - wybór trzpienia

Table III. Parameters of the welding process - selection of the probe

\begin{tabular}{|c|c|c|c|c|c|c|}
\hline Nr próby & Oprawka & Trzpień & Typ połączenia & $\begin{array}{c}\text { Posuw pionowy } \\
\text { Fz [mm/min] }\end{array}$ & $\begin{array}{c}\text { Posuw poziomy } \\
\text { Fx [mm/min] }\end{array}$ & $\begin{array}{c}\text { Prędkość obrotowa } \\
\text { [obr./min] }\end{array}$ \\
\hline 1 & wklęsła & helisoidalny 6 mm & dzp & 8 & 80 & 630 \\
\hline 2 & wklęsła & helisoidalny 6 mm ścięty & dzp & 8 & 80 & 630 \\
\hline 3 & wklęsła & trójramienny & dzp & 8 & 80 & 630 \\
\hline 4 & wklęsła & trójramienny & zak & 8 & 80 & 630 \\
\hline 5 & wklęsła & trójramienny & zak & 8 & 80 & 630 \\
\hline 6 & wklęsła & helisoidalny 7 mm ścięty & zak & 8 & 80 & 630 \\
\hline
\end{tabular}

\section{Urządzenie i parametry procesu}

Testy zgrzewania wykonano adaptując stanowisko wyposażone we frezarkę uniwersalną FU 321 firmy Arsenal. W celu precyzyjnego i stabilnego mocowania elementów stosowano dodatkowe oprzyrządowanie. Próby zgrzewania wykonano dla zmiennych paramentów procesu, tj. prędkość obrotowa, prędkość posuwu wzdłużnego i pionowego. Pierwszy etap badań miał na celu wybór oprawki a drugi najlepszego trzpienia. Warunki przebiegu pierwszego etapu badań przedstawiono w tablicy II. Z kolei w tablicy III zamieszczono parametry procesu zgrzewania zmierzające do wyboru najlepszego trzpienia.

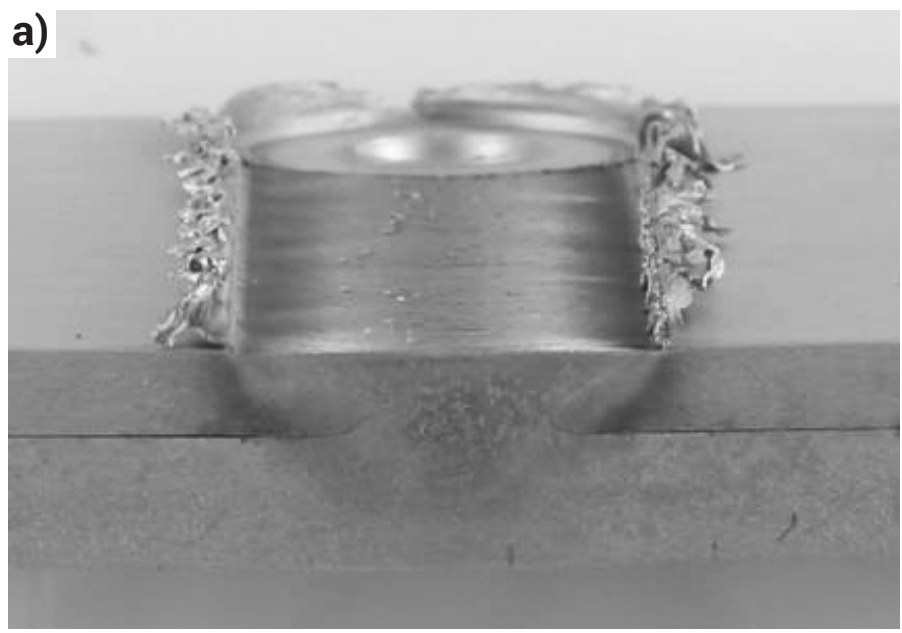

\section{Wyniki badań}

Próby zgrzewania z zastosowaniem oprawek ze helisoidalną powierzchnią tarcia wykazały, iż po obu stronach zgrzeiny formuje się wypchnięty materiał (rys. 4a). Ponadto powierzchnia zgrzeiny po przejściu narzędzia nie jest gładka. Posiada liczne grudki i zadziory (rys. 5a). Tendencja ta występowała dla wszystkich stosowanych wariantów. Natomiast sam materiał jest przemieszany i wolny od niezgodności spawalniczych.

Zgrzeiny wykonane z zastosowaniem oprawek z wklęsłą powierzchnią tarcia charakteryzowały się jednostronnym

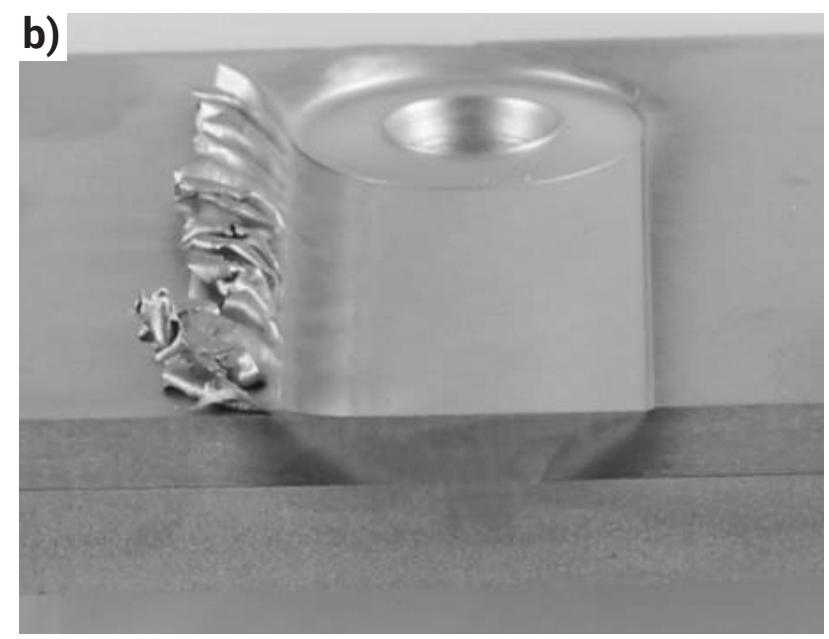

Rys. 4. Typowy przekrój poprzeczny zgrzeiny wykonanej z zastosowaniem oprawki: a) helisoidalnej, b) wklęsłej

Fig. 4. A typical cross-section of a weld made by the probe holders: a) helix, b) concave 
wypchnięciem materiału (rys. 4b). Powstająca tzw. falbana była nieznacznej grubości przez to łatwa do usunięcia. $\mathrm{Na}$ przekroju poprzecznym zgrzeiny nie obserwowano niezgodności spawalniczych. Powierzchnia zgrzeiny była bardzo gładka, regularna o wysokich walorach estetycznych (rys. 5b). Te argumenty zdecydowały, iż badania kontynuowano z zastosowaniem oprawek z wklęsłą powierzchnią tarcia.

Na podstawie badań wykonanych zgodnie z parametrami zamieszczonymi w tablicy III wytypowano trzpień o geometrii warunkującej otrzymywanie zgrzein o wysokiej jakości. Wykazano, iż zastosowanie trzpieni helisoidalnych skutkuje niewystarczającym mieszaniem uplastycznionego materiału,
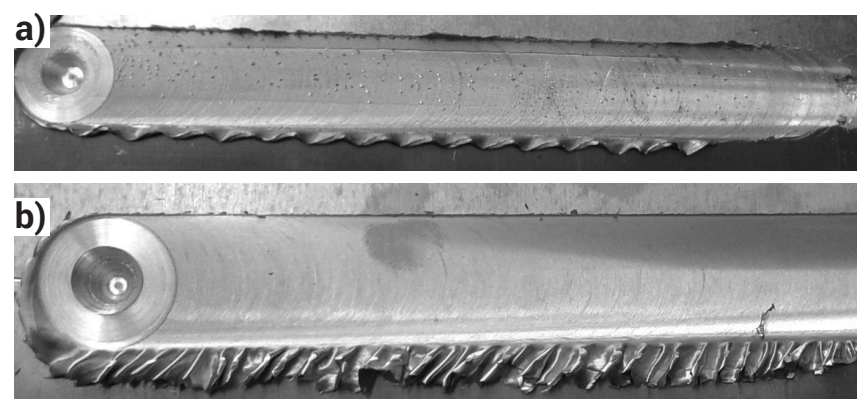

Rys. 5. Widok powierzchni zgrzeiny wykonanej z zastosowaniem oprawki: a) helisoidalnej, b) wklęsłej

Fig. 5. View of the face of the weld made by the probe holders a) helix, b) concave co w efekcie prowadzi do powstawania niezgodności (rys. 6a). Widoczne są pustki oraz przyklejenia zgrzeiny do materiału rodzimego. Zmiana geometrii trzpienia poprzez ścięcie helisy z trzech stron skutkowała zmniejszeniem regularności kształtu trzpienia, co doprowadziło do efektywniejszego mieszania materiału. W efekcie otrzymano zgrzeiny wolne od niezgodności (rys. 6b). Bardzo dobrą jakość zgrzein uzyskano stosując także trzpień helisoidalny trójstronnie ścięty o długości $7 \mathrm{~mm}$ (rys. 6c). Lico jest regularne i stosunkowo płaskie a głębokość zgrzania jest wyraźnie większa niż przy trzpieniu o tej samej geometrii i długości $6 \mathrm{~mm}$. Należy spodziewać się również wyższej wytrzymałości takiego połączenia.

Trzpień trójramienny jest w zasadzie dedykowany do połączeń nakładkowych. Natomiast celem badań był wybór narzędzia warunkującego otrzymywanie poprawnych zgrzein w złączach nakładkowych oraz doczołowych na podkładce. Na rysunku 7 przedstawiono widok zgrzein wykonanych trzpieniem trójramiennym w złączach doczołowym na podkładce i nakładkowym. Lico zgrzein wygląda estetycznie. Na powierzchni nie obserwowano wypchniętego materiału ani gratu. Wysoka jakość zgrzeiny eliminuję obróbkę skrawaniem, a więc ogranicza koszty. Natomiast na przekroju poprzecznym w obu przypadkach obserwowano pustkę na długości całej zgrzeiny. Jest ona również widoczna w miejscu wyjścia narzędzia (rys. 7c). Jest to spowodowane wypychaniem materiału do góry przez szerszy u dołu trzpień.
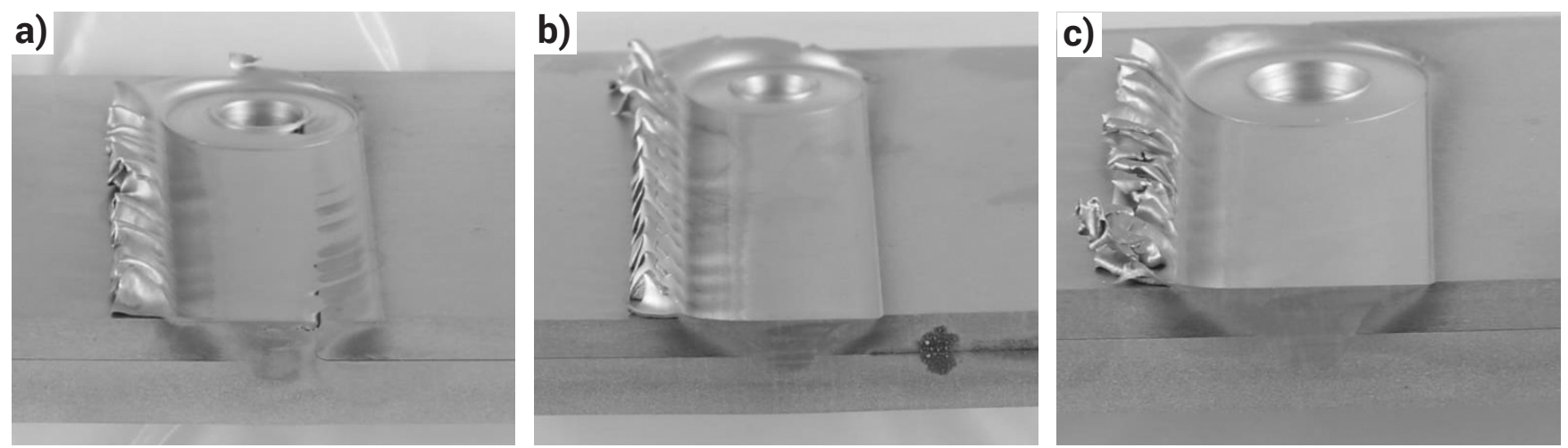

Rys. 6. Przekrój poprzeczny zgrzein wykonanych z zastosowaniem trzpienia: a) helisoidalnego o długości 6 mm, b) helisoidalnego ściętego trójstronnie o długości $6 \mathrm{~mm}$, c) helisoidalnego ściętego trójstronnie o długości $7 \mathrm{~mm}$

Fig. 6. Cross-section of welds made by probe: a) helix with a length of $6 \mathrm{~mm}$, b) helix, cut from three sides, with a length of $6 \mathrm{~mm}, \mathrm{c})$ helix, cut from three sides, with a length of $7 \mathrm{~mm}$

a)

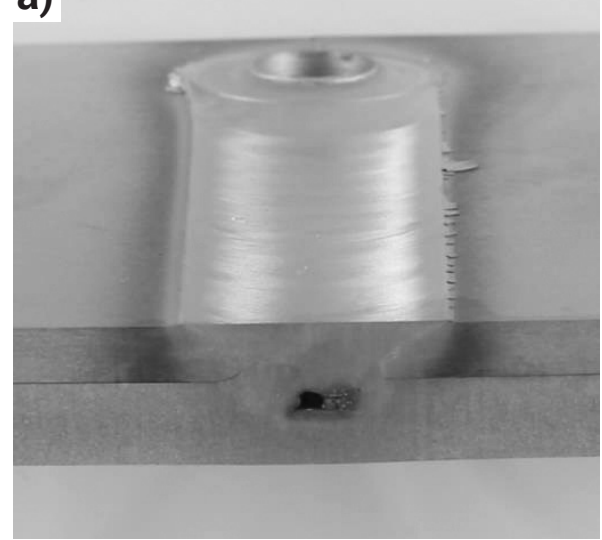

b)

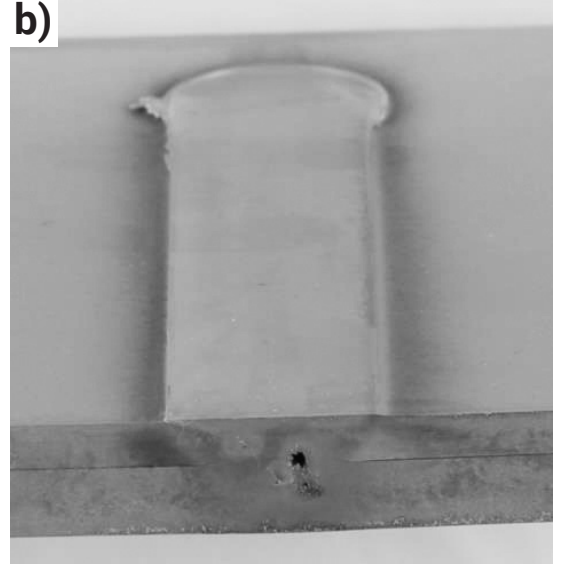

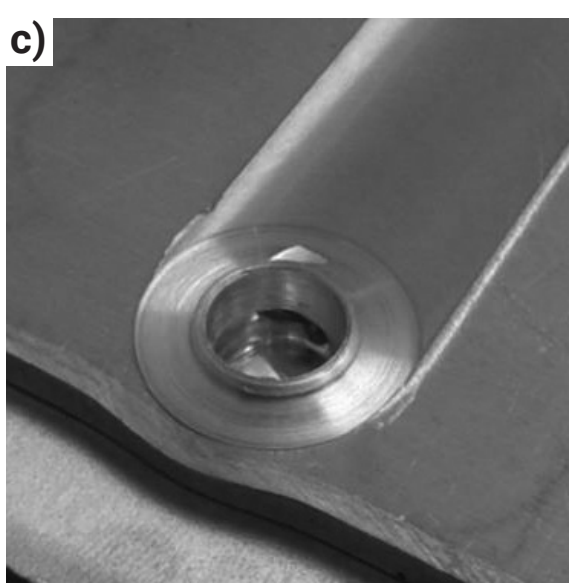

Rys. 7. Widok złączy zgrzewanych wykonanych trzpieniem trójramiennym: a) złącze doczołowe na podkładce, b) złącze nakładkowe, c) obszar wyjścia narzędzia

Fig. 7. View of welded joints made by the three-arm probe: a) strapped butt joints, b) overlap joints, c) tool exit area 


\section{Wnioski}

Na postawie przeprowadzonych badań można wysnuć następujące wnioski:

- Wybór poprawnej geometrii powierzchni tarcia oprawki istotnie wpływa na wygląd lica zgrzeiny. Zastosowanie oprawek z płaską powierzchnią tarcią prowadzi do otrzymania złączy zgrzewanych o znacznie wyższej estetyce niż dla oprawek z powierzchnią w kształcie helisy.

- Trzpienie o helisoidalnej geometrii nie zapewniają właściwego mieszania materiału przez co, zgrzeiny posiadają niezgodności.

- Bardzo dobrą jakość lica zgrzeiny można otrzymać stosując trzpienie trójramienne. Natomiast we wnętrzu zgrzeiny występują niezgodności w postaci pustek i przyklejeń.

- Zmodyfikowane trzpienie helisoidalne poprzez trójstronne ścięcie pobocznicy oferują stosunkowo dobrą jakość lica oraz prawidłowe zgrzanie elementów zarówno w złączach nakładkowym, jak i doczołowym na podkładce.

\section{Literatura}

[1] Lacki P., Derlatka A.: Zastosowanie technologii FSW w strukturach aluminiowych, Obróbka Plastyczna Metali, 2013, vol. XXIV, nr 3, s. 205-218.

[2] Bogucki R., Pietras A., Węglowska A.: Zgrzewanie tarciowe stopu aluminium EN AW-6005A metodą FSW, Szybkobieżne Pojazdy Gąsienicowe, nr 1, (25), 2010, s. 85-100.

[3] Doude H, Schneider J., Patton B., Stafford S., Waters T., Varner C.: Optimizing weld quality of a friction stir welded aluminum alloy, Journal of Materials Processing Technology, 2015, vol. 222, pp. 188-196.

[4] Miara D., Matusiak J.: Wysokowydajne zgrzewanie FSW stopu aluminium przerabianego plastycznie, Przegląd Spawalnictwa, 2017, vol. 89, nr 10, s. 27-31.

[5] El-Sayed M.M., Shash A.Y., Abd-Rabou M.: Finite element modeling of aluminum alloy AA5083-0 friction stir welding process, Journal of Materials Processing Tech., Volume 252, February 2018, pp. 13-24.
[6] Taysoma B.S., Sorensena C.D., Hedengrenb J.D.: Dynamic modeling of friction stir welding for model predictive control, Journal of Manufacturing Processes 23, 2016, pp. 165-174.

[7] Kalemba I., Dymek S.: Mikrostruktura i właściwości połączeń stopów aluminium wykonanych metodą zgrzewania tarciowego z mieszaniem materiału zgrzeiny, Przegląd Spawalnictwa, 2011, vol. 83, nr 7, s. 45-50.

[8] Zhang Y.N., Cao X., Larose S., Wanjara P.: Review fo tools for friciton stir welding and processing, Canadian Metallurgical Quarterly, 2012, vol. 51, no. 3, pp. 250-261.

[9] Wojsyk K., Kudła K.: Analiza konstrukcji i opracowanie geometrii narzędzi do zgrzewania złączy ze stopów metali metodą FSW, Przegląd Spawalnictwa, 2015, vol. 87, $\mathrm{nr} 10$, s. 42-44. 